\title{
Epidemiology, mutational landscape and staging of hepatocellular carcinoma
}

\author{
Sarah E. Fenton, Michael C. Burns, Aparna Kalyan \\ Division of Hematology and Oncology, Robert H. Lurie Comprehensive Cancer Center of Northwestern University, Chicago, IL, USA \\ Contributions: (I) Conception and design: A Kalyan; (II) Administrative support: None; (III) Provision of study materials or patients: None; (IV) \\ Collection and assembly of data: SE Fenton, MC Burns; (V) Data analysis and interpretation: SE Fenton, MC Burns; (VI) Manuscript writing: All \\ authors; (VII) Final approval of manuscript: All authors. \\ Correspondence to: Aparna Kalyan, MBBS. Assistant Professor, Division of Hematology Oncology, Robert H. Lurie Comprehensive Cancer Center of \\ Northwestern University, Chicago, IL 60611, USA. Email: Aparna.kalyan@northwestern.edu.
}

\begin{abstract}
Hepatocellular carcinoma (HCC) is the most common primary cancer of the liver and rates of diagnosis have been fluctuating worldwide. In Western countries, HCC is driven primarily by the hepatitis $\mathrm{C}$ virus (HCV), alcohol use and non-alcoholic fatty liver disease (NAFLD). Hence, it is not surprising that the increased incidence of both HCV and NAFLD has been associated with a corresponding rise in rates of HCC. The introduction of antiviral medications could potentially change the landscape of HCC by reducing rates of $\mathrm{HCV}$-associated HCC. In Eastern countries and Africa, HCC is driven primarily by hepatitis B virus (HBV), HCV, and to a lesser extent, aflatoxin exposure. The introduction of hepatitis $\mathrm{B}$ vaccines is expected to dramatically reduce hepatitis B induced liver damage and HCC. These varying etiologies of HCC result in different mutational landscapes, patient presentations and responses to treatment. This has made establishing a universal staging system difficult and several competing systems are available. Other than Sorafenib, there has also been a paucity of treatment options until the last two years, with immunotherapy and new-targeted tyrosine kinase inhibitors as potential treatment options. Management of HCC offers unique challenges during treatment, as there is often competing illness from underlying liver dysfunction and malignancy itself, both of which affects survival and treatment choice. The new era of treatment may offer additional options in this challenging field. In this review, we describe the underlying etiologies and associated mutational landscape, which drives the treatment options in this complex disease.
\end{abstract}

Keywords: Hepatocellular carcinoma (HCC); epidemiology; staging

Submitted May 27, 2020. Accepted for publication Dec 22, 2020.

doi: $10.21037 / \mathrm{cco}-20-162$

View this article at: http://dx.doi.org/10.21037/cco-20-162

\section{Introduction}

Hepatocellular carcinoma (HCC) makes up 70-90\% of primary liver cancers $(1,2)$. Currently the third leading cause of cancer-related death, HCC is also one of the rapidly increasing causes of mortality in cancer patients $(3,4)$. However, while rates of diagnosis are increasing in Western countries, they are decreasing in many Eastern countries (5). Over the last forty years, the incidence of HCC has quadrupled in the United States due to increased rates of hepatitis $\mathrm{C}$ virus (HCV) infection in the 1960-70s and non-alcoholic fatty liver disease (NAFLD)/ non-alcoholic steatohepatitis (NASH) (Figure 1) (6-10). Fortunately, between 2009 and 2013, rates of HCC diagnosis and mortality have slowed with an anticipated decrease within the next twenty years due to decreased rates of HCV and improved antiviral options $(6,7,10,11)$. Despite these improvements, certain patient populations, including men aged 55-64 across all ethnic backgrounds, continue to have increasing rates of HCC $(5,10)$. In Western populations, HCC is predominantly driven by HCV and alcohol intake (Figure 1) $(12,13)$. Despite decreasing rates 
A

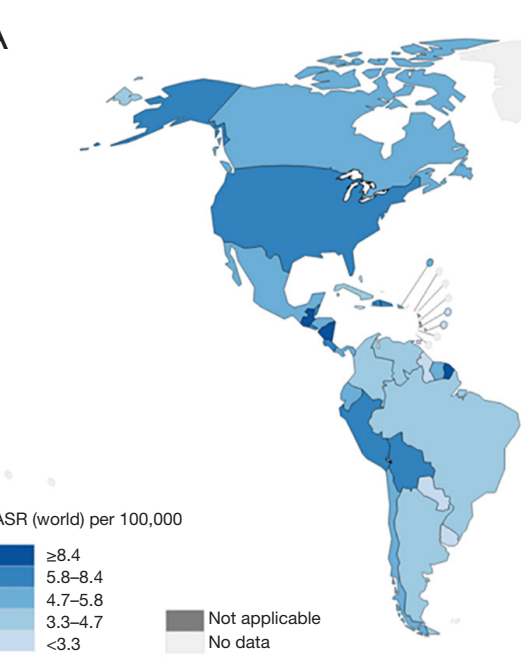

Incidence

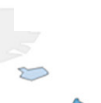

$<x_{0}=$

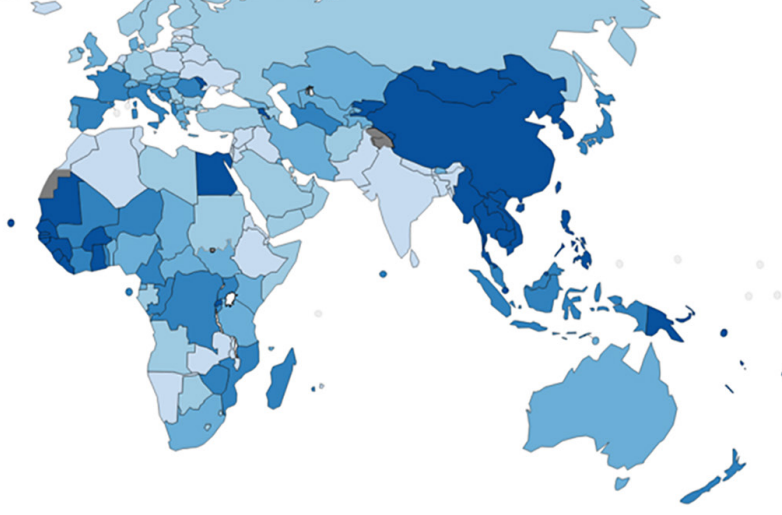

B

Prevalence (5-year)
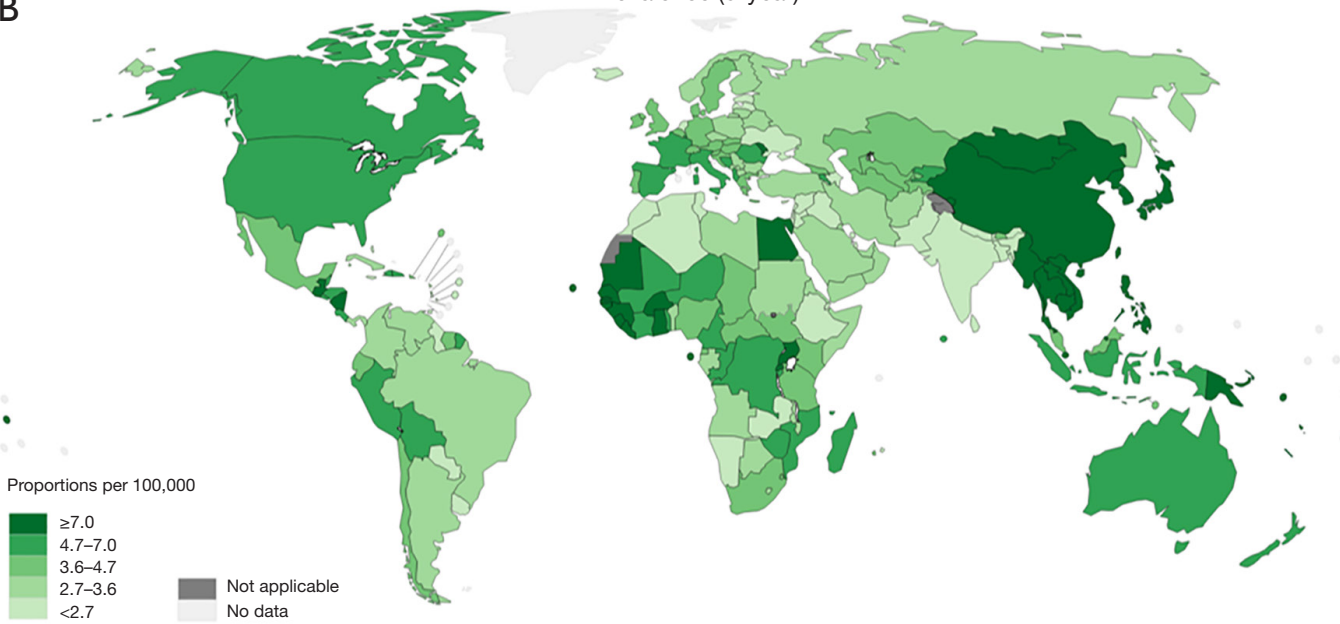

C

Mortality
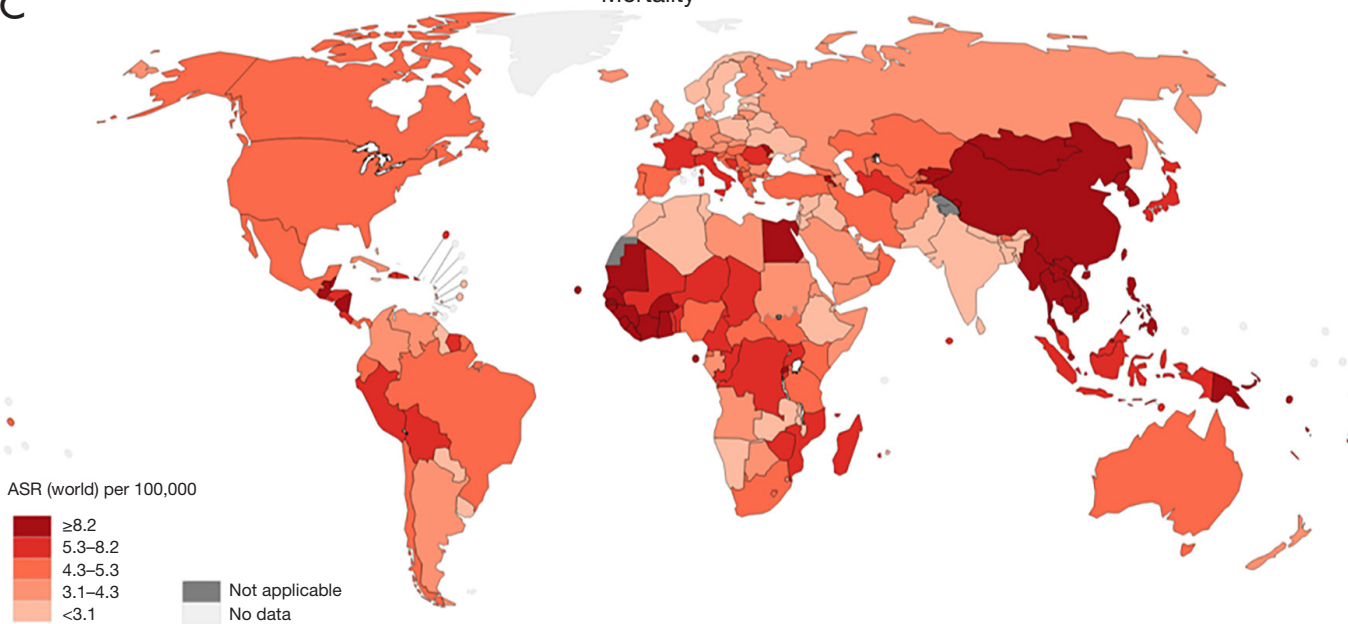

Figure 1 Geographical distribution of HCC. (A) Incidence, (B) prevalence (5-year), and (C) mortality for hepatocellular carcinoma by region. Age standardized rate (ASR) per 100,000 is shown. Data are from the International Agency for Research on Cancer (https://gco.iarc. fr/) (accessed on June 8, 2020). HCC, hepatocellular carcinoma. 
of HCC in Eastern countries, the bulk of HCC diagnoses (approximately 80\%) are still made in sub-Saharan Africa and eastern Asia (50\% in China alone), where the most common risk factors include HBV and exposure to aflatoxin B1 (Figure 1) $(2,12)$. In the United States, the mean age at diagnosis is 65 years old with $74 \%$ of HCC patients being male (14). Although $48 \%$ of HCC patients are Caucasian, the highest incidence is found in Pacific Islanders $(11.7 / 100,000)(15,16)$.

HCC most often arises due to injury to the liver parenchyma, mediated by various insults that lead to the development of cirrhosis (Figure 2). Up to $80-90 \%$ of patients with HCC have concurrent cirrhosis (12), which increases a patient's risk of HCC by 30 fold (17). However, as will be discussed in the following paragraphs, several etiologies of HCC mediate tissue transformation without preceding cirrhosis (Figure 2). As the development of HCC is associated with multiple causes, certain genetic signatures have also been associated with different insults leading to HCC. Common signaling pathways associated with hepatocyte transformation include the p53, Ras, MAPK, JAK/STAT, Wnt/ $\beta$-catenin and Hedghog pathways $(18,19)$. In this review, we will discuss different etiologies of HCC, mutations associated with HCC formation and staging of HCC.

\section{Etiologies of HCC}

\section{$\mathrm{HCV}$}

$\mathrm{HCV}$ is a member of the Flaviviridae family of RNA viruses and infection accounts for approximately $80 \%$ of HCC cases (20). Over 200 million people worldwide and 3.9 million adults in the US are infected with $\operatorname{HCV}(21,22)$. Six genotypes and multiple subtypes of each genotype have been identified (23). The rates of HCV-associated HCC is twice as high in Japan as the United States and Europe, likely due to the increased prevalence of genotype 1B HCV, a more resistant strain of the virus $(15,24,25)$. Genotype $1 \mathrm{~b}$ is also the most common subtype of $\mathrm{HCV}$ in Asia, while genotype 1a and $1 \mathrm{~b}$ are most common in Europe, North and South America and genotype 4 is the most common subtype in Africa (23). Active infection with HCV increases the risk of HCC development by 15-20 fold (5-year cumulative risk of $17 \%$ in Western countries), and this risk is even greater in patients with $\mathrm{HCV}$-induced cirrhosis where the annual risk of HCC is $1-8 \%(12,24,26-29)$. Although antiviral medications have been developed to eradicate $\mathrm{HCV}$ infection, only $50 \%$ of patients are aware of their $\mathrm{HCV}$ diagnosis, limiting the ability of these medications to reduce cirrhosis and HCC risk $(30,31)$.

In the United States, $45-55 \%$ of new HCC cases are associated with $\mathrm{HCV}$ infection (32). Patients with risk factors including infection with $\mathrm{HCV}$ genotype 3, coinfection with HBV or the human immunodeficiency virus (HIV) have an increased risk of HCC (33-39). Heavy alcohol use in particular has a synergistic risk of HCC development in patients with HCV. Approximately $13-23 \%$ of HCC patients have alcohol related disorders $(40,41)$. Additionally, the presence of the $61^{*} \mathrm{G}$ (rs4444903) single nucleotide polymorphism in the epidermal growth factor gene increases the risk of HCC development in patients with HCV (42). PNPLA3, a genetic predisposition identified primarily in Hispanic patients, increases the risk of HCC in patients with chronic HCV or NAFLD (5).

Rates of HCV eradication have increased precipitously with the introduction of direct-acting antivirals (DAAs) and interferon therapy. A sustained virologic response (SVR) is the most significant modifier of HCC development, reducing the risk by $50-80 \%(5,43-46)$. However, eradication of the virus does not completely eliminate the risk of future HCC formation, especially in patients with cirrhosis $(47,48)$. A study of patients treated with DAAs through the Veterans' Affairs system found that patients with a SVR had a lower risk of HCC [HR 0.28, 95\% confidence interval (CI): 0.22-0.36], but the risk of HCC remained higher in patients with cirrhosis (HR 4.71, 95\% CI: 3.34-6.68) (46). A systemic review of 26 studies found that HCC risk was reduced to a similar extent by both DAA and interferon based therapy (49). In Western countries and Japan, HCV remains the most frequent etiology of HCC formation. Hopefully, as DAA and interferon therapy becomes more prevalent, rates of $\mathrm{HCV}$ induced cirrhosis and HCC will decrease in line with what has been seen with $\mathrm{HBV}$ vaccination.

\section{Hepatitis B virus (HBV)}

$\mathrm{HBV}$ is a DNA virus with eight genotypes (A-H). Genotype $\mathrm{C}$ is associated with severe liver disease and increased risk of HCC formation, and is the most common genotype in eastern Asian countries (14,50-54). HBV drives hepatocyte transformation and HCC through chronic necroinflammation and direct hepatocarcinogenesis secondary to virus specific factors (integration into the genome causing rapid cell cycling and instability among other causes) (55-58). 


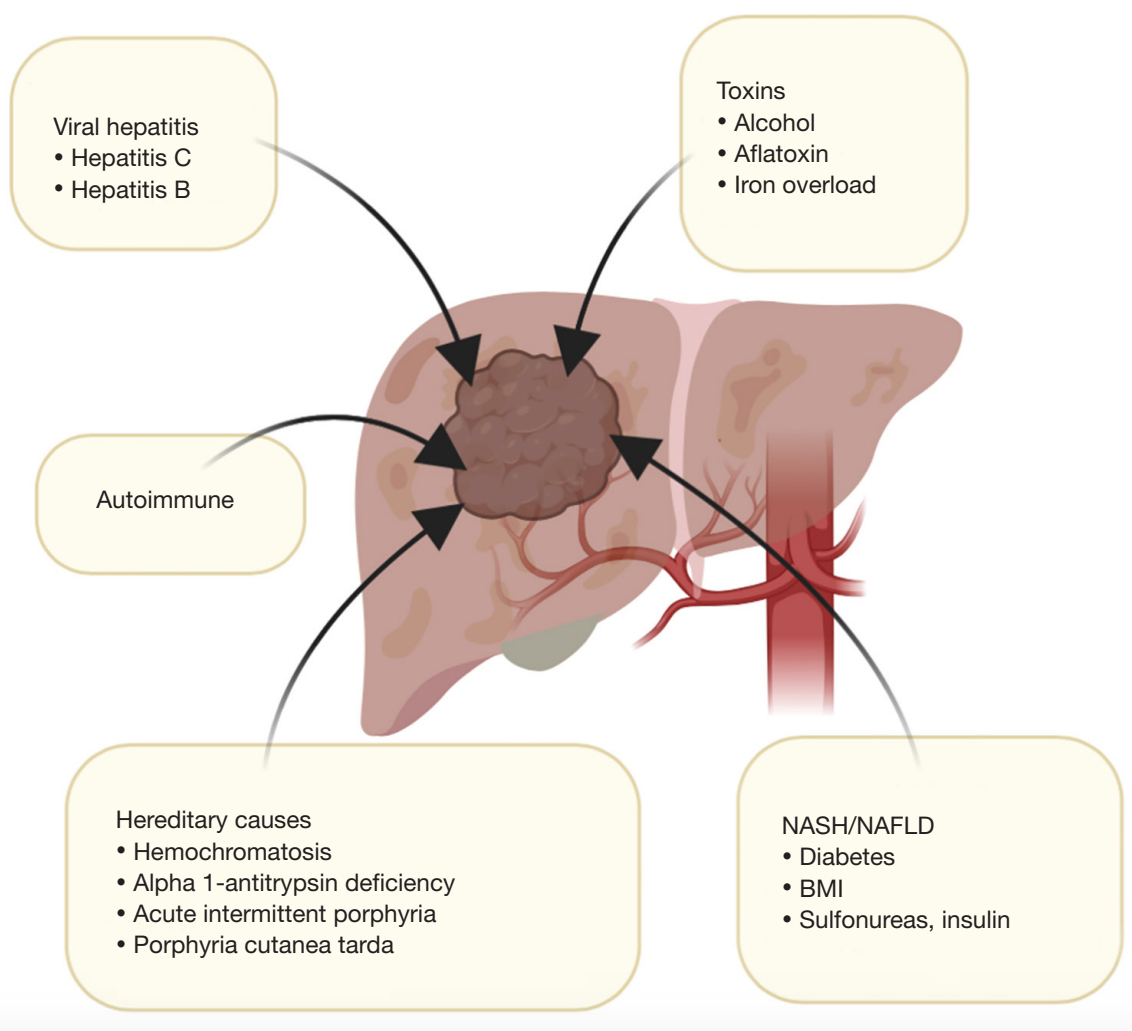

Figure 2 Etiologies of HCC include viral, autoimmune, exposures/toxins, hereditary causes and NASH/NAFLD. These etiologies may or may not act through mechanisms associated with cirrhosis. HCC, hepatocellular carcinoma; NASH, non-alcoholic steatohepatitis; NAFLD, non-alcoholic fatty liver disease.

Between $70 \%$ and $90 \%$ of $\mathrm{HBV}$ infected patients that develop HCC have underlying cirrhosis $(12,59,60)$. Certain risk factors are associated with HCC formation even in the absence of cirrhosis, including: African American and Asian ethnicities, 1-antitrypsin deficiency, Wilson's disease, aflatoxin exposure and family history of HCC (61).

While $\mathrm{HCV}$ is the dominant risk factor in North America, HCC is more frequently driven by $\mathrm{HBV}$ in Africa and Asia, where HBV is often passed from mother to child via vertical transmission (62-64). In fact, the first documentation of the association between HBV and HCC was made in Taiwan in 1981 (65). Infection with $\mathrm{HBV}$ is associated with a $10 \%$ risk of HCC formation in Western countries and a $15 \%$ risk of HCC formation in Asia $(24,29)$. In the United States, there are approximately 860,000 patients with chronic HBV infections, most of whom emigrated from countries with high endemic rates of HBV (66). Ten to fifteen percent of new HCC cases in the United States are due to HBV (32). The introduction of routine $\mathrm{HBV}$ vaccination is thought to contribute to this significant decrease in prevalence compared to other countries $(32,67)$. A study in Taiwan found that HBV seropositivity rates decreased from $10-17 \%$ to $0.7-1.7 \%$ after the introduction of the HBV vaccine (68). Similar to HCV, DAA therapy has been developed for HBV but the decrease in HCC risk after successful treatment has not been defined, although early studies suggest it may be close to $50 \%(69,70)$. Risk factors associated with HCC formation after DAA use include older age, the presence of cirrhosis, thrombocytopenia, and increased liver stiffness (71-73).

\section{Alcobol}

Among patients with excessive alcohol intake ( $\geq 3$ drinks/day), $1-2.5 \%$ will develop liver disease annually. Of these patients, $3-12 \%$ of patients annually will progress to cirrhosis, with a lifetime risk of $8-20 \%$ (74-76). Alcohol induced cirrhosis carries an $8-12 \%$ risk of progressing to HCC. The relative risk of HCC in heavy drinkers, 
TERT promoter

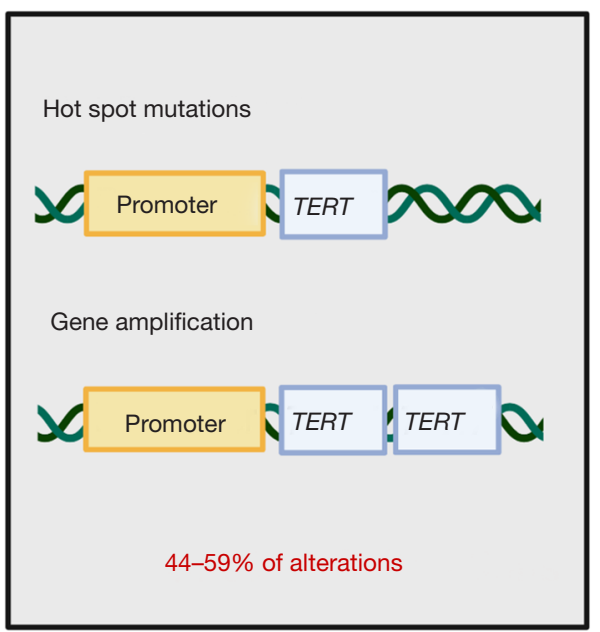

p53 pathway
WNT/ $\beta$-catenin pathway

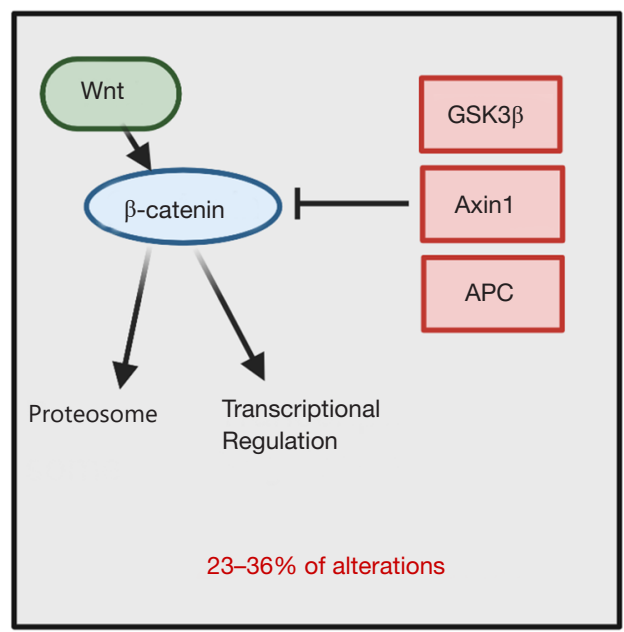

$23-36 \%$ of alterations

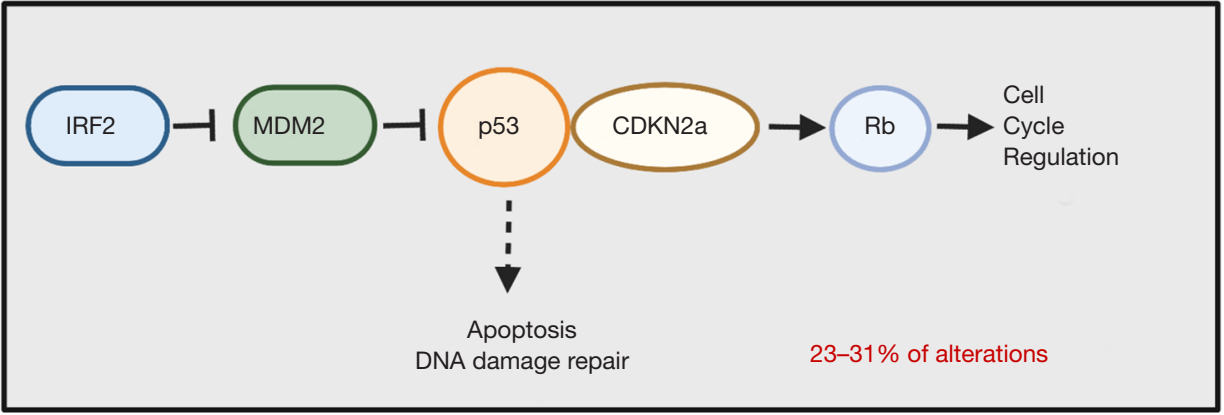

Figure 3 Somatic alterations commonly detected in HCC include those in the TERT promoter resulting in increased telomerase activity, the $\mathrm{Wnt} / \beta$-catenin pathway resulting in gene dysregulation and the p53 pathway altering mechanisms involved in DNA damage repair and apoptosis. HCC, hepatocellular carcinoma.

regardless of the presence of cirrhosis, is 1.16 (95\% CI: $1.01-1.34)(24,29,77)$. The risk of HCC decreases by 6-7\%/year in abstinent patients; after twenty three years, the risk of HCC returns to that of nondrinkers, even in the setting of cirrhosis (78). Unfortunately, the presence of hepatitis, fatty liver, tobacco use or obesity in a patient with excessive alcohol consumption synergistically increases the risk of HCC $(27,79-81)$. Specifically, the combination of HCV and excessive alcohol intake increases the risk of HCC compared to alcohol intake alone (HR 11.2, 95\% CI: 2.3-55). Tumors related to combination of HCV and excessive alcohol intake are less differentiated, suggesting a more aggressive course $(82,83)$.

\section{NAFLD/NASH}

Thirty to forty percent of new HCC cases are associated with metabolic disorders (metabolic syndrome, diabetes mellitus and obesity); however the exact mechanism of HCC in NAFLD/NASH is unknown $(40,84,85)$. Up to one third of the population of the United States has NAFLD, with 10-20\% ultimately developing cirrhosis (86-89), although up to $20 \%$ of patients with NAFLD and HCC show no evidence of cirrhosis (90). A VA study of patients with NAFLD found the hazard ratio of developing HCC was 7.62 (95\% CI: 5.76-10.1) (90). However, in the United States, NAFLD is the most frequent cause of HCC in the absence of cirrhosis or liver fibrosis (91). Because NAFLD leads to cirrhosis and HCC to a much lesser extent than the risk factors discussed above and the mechanism is not as well defined, it is difficult to predict who may be at increased risk of hepatocyte transformation $(14,92,93)$. Despite this, NAFLD/NASH is the fastest growing etiology of HCC in the United States and will continue to impact 
fatality rates from HCC (94-97).

Risk factors associated with HCC formation include duration of type II diabetes mellitus, a high hemoglobin A1C, sulfonylurea use, or insulin therapy $(98,99)$. A diagnosis of diabetes mellitus alone increases the risk of HCC two to three fold, regardless of the presence of hepatic damage (41). Interestingly, metformin use is associated with a $50 \%$ decreased risk of HCC through activation of the MAPK pathway and signaling through RAS/RAF/MEK/ ERK, PI3K/AKT/mTOR and Wnt/ $\beta$-catenin (98-104). The presence of a single nucleotide polymorphism in the palatin-like phospholipase domain-containing protein 3 (PNPLA3) or rs738409 may increase the risk of HCC in patients with NAFLD (105). Additionally, regardless of the etiology of HCC, the presence of an elevated body mass index (BMI) of 35-40 is associated with a 5-fold increase in liver cancer mortality (106).

\section{Aflatoxin}

Aflatoxin is produced by the molds Aspergillus flavus and Aspergillus parasiticus and is found in grains, maize, legumes, tree and grout nuts and the milk of animals that eat these products (67). Over 55 million people are exposed worldwide, predominantly in Mozambique, Vietnam, China and India (67). Between 4.6-28.2\% of HCC cases are associated with aflatoxin exposure and this is particularly notable in patients with $\mathrm{HBV}$ and excessive alcohol use, where it synergistically increases the risk of $\operatorname{HCC}(107,108)$. Thirty to sixty percent of HCC tumors from areas known to have aflatoxin contain mutations associated with aflatoxin metabolite induced DNA damage, including mutations in codon 249 of $\mathrm{p} 53(\mathrm{G}>\mathrm{T})(109-111)$.

\section{Hereditary causes}

Several hereditary disorders that cause liver damage are associated with HCC development. Hemochromatosis is an autosomal recessive disorder driven by missense mutations in the HFE gene (C282y and H63D) on chromosome six, where excess iron is reabsorbed and deposited in the liver among other tissues. Inheritance of hemochromatosis increases a patient's risk of HCC by 20 fold and carries a $21 \%$ lifetime risk of HCC development $(24,29,112,113)$. Alpha 1-antitrypsin deficiency, acute intermittent porphyria and porphyria cutanea tarda are other hereditary conditions associated with liver damage and an increased risk of $\operatorname{HCC}(114,115)$.

\section{Autoimmune bepatitis}

Autoimmune hepatitis increases the risk of liver damage, cirrhosis and HCC but is lower compared to viral hepatitis. The incidence rate is 3.06 per 1,000 patient years $(95 \% \mathrm{CI}$ : 2.22-4.23) in patients without cirrhosis and 10.07 per 1,000 patient years (95\% CI: 6.89-14.7) with cirrhosis $(69,116)$. Multiple autoimmune relapses and ongoing alcohol abuse account for increased incidence of autoimmune mediated HCC (32).

\section{Protective factors}

Several lifestyle changes are associated with a decreased likelihood of HCC formation. Statin use decreases the risk of HCC in a dose dependent manner through 3-hydroxy3 -methylglytaryl coenzyme A inhibition $(66,100,117)$, with Asian patients reaping the greatest benefit (100). As discussed above, metformin use is associated with decreased risk of HCC in patients with type II diabetes mellitus (102). HCC risk is also reduced by propranolol in patients with HCV related cirrhosis (118).

\section{Mutational landscape}

The most frequent somatic alterations observed in HCC occur in genes that are not clinically actionable, including the TERT promoter (44-59\%), TP53 (23-31\%) and the WNT pathway oncogene CTNNB1 (23-36\%) (Figure 3) $(119,120)$. Alterations at the TERT promoter by mutation, amplification, or hepatitis B DNA insertion serve to increase telomerase activity $(121,122)$. Such TERT promoter point mutations have been shown to frequently co-occur with WNT pathway alterations, including activating mutations in $C T N N B 1$ (the gene encoding $\beta$-catenin) or loss of function alterations in the $A X I N 1$ (5-10\%) and $A P C(1-2 \%)$ genes (123). Alterations in CTNNB1 and TERT promoter, as well as the tumor suppressor $C D K N 2 A$, are also frequently enriched in alcohol-related HCC (124). These data suggest cooperativity between telomere maintenance and the WNT pathway in HCC. In contrast to TERT promoter mutations, mutations in TP53 are associated with aflatoxin B1 exposure and HBV-related HCC and have been shown to be mutually exclusive with CTNNB1 mutations $(124,125)$. Tumor suppressor alterations in TP53 and $C D K N 2 A$ are often late occurring and associated with aggressive forms of HCC that carry a poor prognosis (125). Other less frequent genomic alterations in HCC occur in pathways regulating 
chromatin modification (ARID1A, ARID2, MLL1/MLL2/ $M L L 3 / M L L 4)$, receptor tyrosine kinase (RTK)-Ras-PI3K signaling cascades (EGFR/ PDGFR/PIK3CA/PTEN/KRAS) and oxidative stress (NFE2L2/KEAP1) (119,120).

Characterization of the recurrent genomic alterations described above has allowed for the identification of actionable therapeutic targets and provided the basis for the molecular subclassification of HCC $(126,127)$. Two primary molecular subtypes of HCC have been described $(120,128)$. The proliferative class is associated with a poor prognosis, chromosomal instability, and aberrant activation of the RTK-RAS-MAPK signaling cascade and PI3KAKT-mTOR pathway. A second non-proliferative class, less aggressive clinically and driven by WNT signaling, retains similar physiology to normal hepatocytes and may have increased susceptibility to sorafenib (129). Finally, while anti-PD-1/PD-L1 immunotherapies are increasingly being used to treat HCC, correlative studies with nivolumab in advanced HCC (CheckMate 040) did not show a correlation with PD-L1 expression (130), and the molecular characterization of an immune-specific class of HCC remains an active area of investigation (131).

\section{Staging}

Unfortunately, HCC is often diagnosed at later stages due to its silent nature and lack of symptoms until the tumor burden is relatively high (14). Several staging systems have been developed in an attempt to provide prognostic information based on tumor and patient characteristics, direct therapies and to stratify patients in clinical trials. At least thirteen staging systems have been developed in an attempt to codify this information, more than have been developed for any other type of cancer. Unfortunately, none of these systems have been definitively proven to be superior, likely due to the heterogeneous nature of HCC and the many etiologies that can lead to HCC formation (132).

The Barcelona Clinic Liver Cancer (BCLC) system is the most commonly used staging system worldwide (3). It splits patients into five stages based on the number and size of lesions, locoregional involvement, patient characteristics and liver function tests. Tumor extension incorporates the number of tumors, tumor size and presence of portal vein invasion or extra-hepatic metastasis (3). Each stage has an associated prognosis and treatment plan.

\section{Conclusions}

HCC remains a malignancy that places a high burden on healthcare systems and patients worldwide with a ratio of mortality to incidence of 0.95 (2). Several causes of HCC have been identified including HCV, HBV and NAFLD/ $\mathrm{NASH}$, among others. Interestingly, the incidence of these driving factors varies geographically, changing the mutational landscapes that predominate around the world. Because HCC is a multifactorial malignancy with different inciting events and mutational burdens, it is difficult to identify a consistent system of codification. Ultimately, further understanding of the genomic landscape will lead to changes in the treatment strategies.

\section{Acknowledgments}

Funding: None.

\section{Footnote}

Provenance and Peer Review: This article was commissioned by the Guest Editors (Mehmet Akce and Shishir K. Maithel) for the series "Hepatocellular Carcinoma" published in Chinese Clinical Oncology. The article was sent for external peer review organized by the Guest Editors and the editorial office.

Conflicts of Interest: All authors have completed the ICMJE uniform disclosure form (available at http://dx.doi. org/10.21037/cco-20-162). The series "Hepatocellular Carcinoma" was commissioned by the editorial office without any funding or sponsorship. AK reports other from Bristol-Myers Squibb, outside the submitted work. The authors have no other conflicts of interest to declare.

Ethical Statement: The authors are accountable for all aspects of the work in ensuring that questions related to the accuracy or integrity of any part of the work are appropriately investigated and resolved.

Open Access Statement: This is an Open Access article distributed in accordance with the Creative Commons Attribution-NonCommercial-NoDerivs 4.0 International License (CC BY-NC-ND 4.0), which permits the noncommercial replication and distribution of the article with the strict proviso that no changes or edits are made and the 
original work is properly cited (including links to both the formal publication through the relevant DOI and the license). See: https://creativecommons.org/licenses/by-nc-nd/4.0/.

\section{References}

1. Altekruse SF, Devesa SS, Dickie LA, et al. Histological classification of liver and intrahepatic bile duct cancers in SEER registries. J Registry Manag 2011;38:201-5.

2. Ferlay J, Shin HR, Bray F, et al. Estimates of worldwide burden of cancer in 2008: GLOBOCAN 2008. Int J Cancer 201:2893-917.

3. Forner A, Reig M, Bruix J. Hepatocellular carcinoma. Lancet 2018;391:1301-14.

4. Siegel RL, Miller KD, Jemal A. Cancer statistics, 2016. CA Cancer J Clin 2016;66:7-30

5. Kulik L, El-Serag GB. Epidemiology and Management of Hepatocellular Carcinoma. Gastroenterology 2019;156:477-491.e1.

6. Petrick JL, Kelly SP, Altekruse SF, et al. Future of hepatocellular carcinoma incidence in the United States forecast through 2030. J Clin Oncol 2016;34:1787-94.

7. Davis GL, Alter MJ, El-Serag H, et al. Aging of hepatitis $\mathrm{C}$ virus (HCV)-infected persons in the United States: a multiple cohort model of $\mathrm{HCV}$ prevalence and disease progression. Gastroenterology 2010;138:513-21, 521.e1-6.

8. Davila JA, El-Serag HB. The rising incidence of hepatocellular carcinoma in the United States: an update. Gastroenterology 2012;142:S914.

9. Singal AG, El-Serag HB. Hepatocellular carcinoma from epidemiology to prevention: translating knowledge into practice. Clin Gastroenterol Hepatol 2015;13:2140-51.

10. White DL, Thrift AP, Kanwal F, et al. Incidence of hepatocellular carcinoma in all 50 United States, from 2000 through 2012. Gastroenterology 2017;152:812820.e5.

11. Altekruse SF, Henley SJ, Cucinelli JE, et al. Changing hepatocellular carcinoma incidence and liver cancer mortality rates in the United States. Am J Gastroenterol 2014;109:542-53.

12. El-Serag HB. Epidemiology of viral hepatitis and hepatocellular carcinoma. Gastroenterology 2012;142:1264-1273.e1.

13. Morgan TR, Mandayam S, Jamal MM. Alcohol and hepatocellular carcinoma. Gastroenterology 2004;127:S87-S96.

14. Massarweh NN, El-Serag HB. Epidemiology of hepatocellular carcinoma and intrahepatic cholangiocarcinoma. Cancer Control 2017;24:1073274817729245.

15. El-Serag HB, Rudolph KL. Hepatocellular carcinoma: epidemiology and molecular carcinogenesis. Gastroenterology 2007;132:2557-76.

16. Altekruse SF, McGlynn KA, Reichman ME. Hepatocellular carcinoma incidence, mortality, and survival trends in the United States from 1975 to 2005. J Clin Oncol 2009;27:1485-91.

17. Thiele $M$, Gluud LL, Fialla AD, et al. Large variations in risk of hepatocellular carcinoma and mortality in treatment naive hepatitis B patients: systematic review with metaanalyses. PLoS One 2014;9:e107177.

18. Branda $M$, Wands J. Signal transduction cascades and hepatitis $\mathrm{B}$ and $\mathrm{C}$ related hepatocellular carcinoma. Hepatology 2006;43:891-902.

19. Tsai WL, Chung RT. Viral hepatocarcinogenesis. Oncogene 2010;29:2309-24.

20. El-Serag HB, Kanwal F. Epidemiology of hepatocellular carcinoma in the United States: where are we? Where do we go? Hepatology 2014;60:1767-75.

21. Yoshizawa H. Hepatocellular carcinoma associated with hepatitis $\mathrm{C}$ virus infection in Japan: projection to other countries in the foreseeable future. Oncology 2002;62:8-17.

22. Rosenberg ES, Hall EW, Sullivan PS, et al. Estimation of state-level prevalence of hepatitis $C$ virus infection, US states and District of Columbia 2010. Clin Infect Dis 2017;64:1573-81.

23. Zaltron S, Spinetti A, Biasi L, et al. Chronic HCV infection: epidemiological and clinical relevance. BMC Infect Dis 2012;12:S2-S7.

24. Fattovich G, Stroffolini T, Zagni I, et al. Hepatocellular carcinoma in cirrhosis: incidence and risk factors. Gastroenterology 2004;127:S35-50.

25. Pellicelli AM, Romano M, Stroffolini T, et al. HCV genotype 1a shows a better virologic response to antiviral therapy than HCV genotype 1b. BMC Gastroenterol 2012;12:162.

26. Lok AS, Seeff LB, Morgan TR, et al. Incidence of hepatocellular carcinoma and associated risk factors in hepatitis C-related advanced liver disease. Gastroenterology 2009;136:138-48.

27. Donato F, Tagger A, Gelatti U, et al. Alcohol and hepatocellular carcinoma: the effect of lifetime intake and hepatitis virus infections in men and women. Am J Epidemiol 2002;155:323-31.

28. Sangiovanni A, Del Ninno E, Fasani P, et al. Increased survival of cirrhotic patients with a hepatocellular 
carcinoma detected during surveillance. Gastroenterology 2004;126:1005-14.

29. Chen CJ, Yang HI, Iloeje UH, et al. Hepatitis B virus DNA levels and outcomes in chronic hepatitis B. Hepatology 2009;49:S72-84.

30. Volk ML, Tocco R, Saini S, et al. Public health impact of antiviral therapy for hepatitis $\mathrm{C}$ in the United States. Hepatology 2009;50:1750-5.

31. Thrift AP, El-Serag HB, Kanwal F. Global epidemiology and burden of HCV infection and HCV-related disease. Nat Rev Gastroenterol Hepatol 2017;14:122-32.

32. Mittal S, El-Serag H. Epidemiology of hepatocellular carcinoma: consider the population. J Clin Gastroenterol 2013;47:S2-S6.

33. Kanwal F, Kramer JR, Ilyas J, et al. HCV genotype 3 is associated with an increased risk of cirrhosis and hepatocellular cancer in a national sample of U.S. Veterans with HCV. Hepatology 2014;60:98-105.

34. Freeman AJ, Dore GJ, Law MG, et al. Estimating progression to cirrhosis in chronic hepatitis $\mathrm{C}$ virus infection. Hepatology 2001;34:809-16.

35. Kattakuzhy S, Levy R, Rosenthal E, et al. Hepatitis C genotype 3 disease. Hepatol Int 2016;10:861-70.

36. Poynard T, Bedossa P, Opolon P. Natural history of liver fibrosis progression in patients with chronic hepatitis $\mathrm{C}$. The OBSVIRC, METAVIR, CLINIVIR, and DOSVIRC groups. Lancet 1997;349:825-32.

37. Chang KC, Wu YY, Hung CH, et al. Clinical-guide risk prediction of hepatocellular carcinoma development in chronic hepatitis $\mathrm{C}$ patients after interferon-based therapy. Br J Cancer 2013;109:2481-8.

38. Shindo M, Arai K, Sokawa Y, et al. The virological and histological states of anti-hepatitis $\mathrm{C}$ virus-positive subjects with normal liver biochemical values. Hepatology 1995;22:418-25.

39. Mathurin P, Moussalli J, Cadranel J, et al. Slow progression rate of fibrosis in hepatitis $\mathrm{C}$ virus patients with persistently normal alanine transaminase activity. Hepatology 1998;27:868-72.

40. Makarova-Rusher OV, Altekruse SF, McNeel TS, et al. Population attributable fractions of risk factors for hepatocellular carcinoma in the United States. Cancer 2016;122:1757-65.

41. Welzel TM, Graubard BI, Quraishi S, et al. Population attributable fractions of risk factors for hepatocellular carcinoma in the United States. Am J Gastroenterol 2013;108:1314-21.

42. Abu Dayyeh BK, Yang M, Fuchs BC, et al. A functional polymorphism in the epidermal growth factor gene is associated with risk for hepatocellular carcinoma. Gastroenterology 2011;141:141-9.

43. Huang AC, Mehta N, Dodge JL, et al. Direct-acting antivirals do not increase the risk of hepatocellular carcinoma recurrence after local-regional therapy or liver transplant waitlist dropout. Hepatology 2018;68:449-61.

44. Ioannou GN, Green PK, Berry K. HCV eradication induced by direct-acting antiviral agents reduces the risk of hepatocellular carcinoma. J Hepatol 2017;68:25-32.

45. ANRS collaborative study group on hepatocellular carcinoma. Lack of evidence of an effect of direct acting antivirals on the recurrence of hepatocellular carcinoma. J Hepatol 2016;65:734-40.

46. Kanwal F, Kramer J, Asch SM, et al. Risk of hepatocellular cancer in $\mathrm{HCV}$ patients treated with direct-acting antiviral agents. Gastroenterology 2017;153:996-1005.e1

47. Papatheodoridis GV, Chan HL, Hansen BE, et al. Risk of hepatocellular carcinoma in chronic hepatitis B: assessment and modification with current antiviral therapy. J Hepatol 2015;62:956-67.

48. Singal AK, Singh A, Jaganmohan S, et al. Antiviral therapy reduces risk of hepatocellular carcinoma in patients with hepatitis C virus-related cirrhosis. Clin Gastroenterol Hepatol 2010;8:192-9.

49. Waziry R, Hajarizadeh B, Grebely J, et al. Hepatocellular carcinoma risk following direct-acting antiviral $\mathrm{HCV}$ therapy: a systematic review, meta-analyses, and metaregression. J Hepatol 2017;67:1204-12.

50. McMahon BJ. The influence of hepatitis B virus genotype and subgenotype on the natural history of chronic hepatitis B. Hepatol Int 2009;3:334-42.

51. Chan HL, Hui AY, Wong ML, et al. Genotype C hepatitis $B$ virus infection is associated with an increased risk of hepatocellular carcinoma. Gut 2004;53:1494-8.

52. Kao JH, Chen PJ, Lai MY, et al. Hepatitis B genotypes correlate with clinical outcomes in patients with chronic hepatitis B. Gastroenterology 2000;118:554-9.

53. Lee CM, Chen CH, Lu SN, et al. Prevalence and clinical implications of hepatitis B virus genotypes in southern Taiwan. Scand J Gastroenterol 2003;38:95-101.

54. Tangkijvanich $\mathrm{P}$, Mahachai V, Komolmit P, et al. Hepatitis $\mathrm{B}$ virus genotypes and hepatocellular carcinoma in Thailand. World J Gastroenterol 2005;11:2238-43.

55. Chisari FV. Rous-Whipple award lecture. Viruses, immunity, and cancer: lessons from hepatitis B. Am J Pathol 2000;156:1117-32.

56. Dandri M, Burda M, Bürkle A, et al. Increase in de 
novo HBV DNA integrations in response to oxidative DNA damage or inhibition of poly(ADP-ribosyl)ation. Hepatology 2002;35:217-23.

57. Bonilla Guerrero R, Roberts L. The role of hepatitis $B$ virus integrations in the pathogenesis of human hepatocellular carcinoma. J Hepatol 2005;42:760-77.

58. Ferber MJ, Montoya DP, Yu C, et al. Integrations of the hepatitis $\mathrm{B}$ virus (HBV) and human papillomavirus (HPV) into the human telomerase reverse transcriptase (hTERT) gene in liver and cervical cancers. Oncogene 2003;22:3813-20.

59. Yang JD, Kim WR, Coelho R, et al. Cirrhosis is present in most patients with hepatitis B and hepatocellular carcinoma. Clin Gastroenterol Hepatol 2011;9:64-70.

60. Gaddikeri S, McNeeley MF, Wang CL, et al. Hepatocellular carcinoma in the noncirrhotic liver. AJR Am J Roentgenol 2014;203:W34-47.

61. Chayanupatkul M, Omino R, Mittal S, et al. Hepatocellular carcinoma in the absence of cirrhosis in patients with chronic hepatitis B virus infection. J Hepatol 2017;66:355-62.

62. Clark T, Maximin S, Meier J, et al. Hepatocellular carcinoma: review of epidemiology, screening, imaging diagnosis, response assessment and treatment. Curr Probl Diagn Radiol 2015;44:479-86.

63. Shariff MI, Cox IJ, Gomaa AI, et al. Hepatocellular carcinoma: current trends in worldwide epidemiology, risk factors, diagnosis and therapeutics. Expert Rev Gastroenterol Hepatol 2009;3:353-67.

64. Custer B, Sullivan S, Hazlet T, et al. Global epidemiology of hepatitis B virus. J Clin Gastroenterol 2004;38:S158-68.

65. Beasley RP, Hwang LY, Lin CC, et al. Hepatocellular carcinoma and hepatitis $\mathrm{B}$ virus: a prospective study of 22,707 men in Taiwan. Lancet 1981;2:1129-33.

66. Kim HS, Rotundo L, Yang JD, et al. Racial/ethnic disparities in the prevalence and awareness of hepatitis B virus infection and immunity in the United States. J Viral Hepat 2017;24:1052-66.

67. Lafaro KJ, Demirjian AN, Pawlik TM. Epidemiology of hepatocellular carcinoma. Surg Oncol Clin N Am 2015;24:1-17.

68. Chang MH, You SL, Chen CJ, et al. Decreased incidence of hepatocellular carcinoma in hepatitis B vaccinees: a 20-year follow-up study. J Natl Cancer Inst 2009;101:1348-55.

69. Kim HS, El-Serag HB. The epidemiology of hepatocellular carcinoma in the USA. Curr Gastroenterol Rep 2019;21:17.
70. Liaw YF, Sung JJ, Chow WC, et al. Lamivudine for patients with chronic hepatitis $\mathrm{B}$ and advanced liver disease. N Engl J Med 2004;351:1521-31.

71. Hsu YC, Wu CY, Lane HY, et al. Determinants of hepatocellular carcinoma in cirrhotic patients treated with nucleos $(t)$ ide analogues for chronic hepatitis. J Antimicrob Chemother 2014;69:1920-7.

72. Papatheodoridis GV, Dalekos GN, Yurdaydin C, et al. Incidence and predictors of hepatocellular carcinoma in Caucasian chronic hepatitis B patients receiving entecavir or tenofovir. J Hepatol 2015;62:363-70.

73. Raffetti E, Fattovich G, Donato F. Incidence of hepatocellular carcinoma in untreated subjects with chronic hepatitis B: a systematic review and meta-analysis. Liver Int 2016;36:1239-51.

74. Younossi ZM, Stepanova M, Afendy M, et al. Changes in the prevalence of the most common causes of chronic liver diseases in the United States from 1988 to 2008. Clin Gastroenterol Hepatol 2011;9:524-530.e1.

75. Deleuran T, Gronbaek H, Vilstrup H, et al. Cirrhosis and mortality risks of biopsy-verified alcoholic pure steatosis and steatohepatitis: a nationwide registry-based study. Aliment Pharmacol Ther 2012;35:1336-42.

76. Zhu H, Jia Z, Misra H, et al. Oxidative stress and redox signaling mechanisms of alcoholic liver disease: updated experimental and clinical evidence. J Dig Dis 2012;13:133-42.

77. Turati F, Galeone C, Rota M, et al. Alcohol and liver cancer: a systematic review and meta-analysis of prospective studies. Ann Oncol 2014;25:1526-35.

78. Heckley GA, Jarl J, Asamoah BO, et al. How the risk of liver cancer changes after alcohol cessation: a review and meta-analysis of the current literature. BMC Cancer 2011;11:446.

79. Hutchinson SJ, Bird SM, Goldberg DJ. Influence of alcohol on the progression of hepatitis $\mathrm{C}$ virus infection: a meta-analysis. Clin Gastroenterol Hepatol 2005;3:1150-9.

80. Yuan JM, Govindarajan S, Arakawa K, et al. Synergism of alcohol, diabetes, and viral hepatitis on the risk of hepatocellular carcinoma in blacks and whites in the US. Cancer 2004;101:1009-17.

81. Kuper H, Tzonou A, Kaklamani E, et al. Tobacco smoking, alcohol consumption and their interaction in the causation of hepatocellular carcinoma. Int J Cancer 2000;85:498-502.

82. Berman K, Tandra S, Vuppalanchi R, et al. Hepatic and extrahepatic cancer in cirrhosis: a longitudinal cohort study. Am J Gastroenterol 2011;106:899-906. 
83. Kubo S, Kinoshita H, Hirohashi K, et al. High malignancy of hepatocellular carcinoma in alcoholic patients with hepatitis C virus. Surgery 1997;121:425-9.

84. El-Serag HB, Hampel H, Javadi F. The association between diabetes and hepatocellular carcinoma: a systematic review of epidemiologic evidence. Clin Gastroenterol Hepatol 2006;4:369-80.

85. Wang C, Wang X, Gong G, et al. Increased risk of hepatocellular carcinoma in patients with diabetes mellitus: a systematic review and meta-analysis of cohort studies. Int J Cancer 2012;130:1639-48.

86. Stepanova M, De Avila L, Afendy M, et al. Direct and indirect economic burden of chronic liver disease in the United States. Clin Gastroenterol Hepatol 2017;15:759-766.e5.

87. Neuschwander-Tetri BA, Caldwell S. Nonalcoholic steatohepatitis: summary of an AASLD Single Topic Conference. Hepatology 2003;37:1202-19.

88. Williams CD, Stengel J, Asike MI, et al. Prevalence of nonalcoholic fatty liver disease and nonalcoholic steatohepatitis among a largely middle-aged population utilizing ultrasound and liver biopsy: a prospective study. Gastroenterology 2011;140:124-31.

89. Ahmed A, Wong RJ, Harrison SA. Nonalcoholic fatty liver disease review: diagnosis, treatment, and outcomes. Clin Gastroenterol Hepatol 2015;13:2062-70.

90. Kanwal F, Kramer JR, Mapakshi S, et al. Risk of hepatocellular cancer in patients with non-alcoholic fatty liver disease. Gastroenterology 2018;155:1828-1837.e2.

91. Mittal S, El-Serag HB, Sada YH, et al. Hepatocellular carcinoma in the absence of cirrhosis in United States veterans is associated with nonalcoholic fatty liver disease. Clin Gastroenterol Hepatol 2016;14:124-31.e1.

92. Schlesinger S, Aleksandrova K, Pischon T, et al. Diabetes mellitus, insulin treatment, diabetes duration, and risk of biliary tract cancer and hepatocellular carcinoma in a European cohort. Ann Oncol 2013;24:2449-55.

93. Tsilidis KK, Kasimis JC, Lopez DS, et al. Type 2 diabetes and cancer: umbrella review of meta-analyses of observational studies. BMJ 2015;350:g7607.

94. Paradis V, Zalinski S, Chelbi E, et al. Hepatocellular carcinomas in patients with metabolic syndrome often develop without significant liver fibrosis: a pathological analysis. Hepatology 2009;49:851-9.

95. Yasui K, Hashimoto E, Komorizono Y, et al. Characteristics of patients with nonalcoholic steatohepatitis who develop hepatocellular carcinoma. Clin Gastroenterol Hepatol 2011;9:428-33.
96. Adams LA, Lindor KD. Nonalcoholic fatty liver disease. Ann Epidemiol 2007;17:863-9.

97. Wong RJ, Cheung R, Ahmed A. Nonalcoholic steatohepatitis is the most rapidly growing indication for liver transplantation in patients with hepatocellular carcinoma in the US. Hepatology 2014;59:2188-95.

98. Mantovani A, Targher G. Type 2 diabetes mellitus and risk of hepatocellular carcinoma: spotlight on nonalcoholic fatty liver disease. Ann Transl Med 2017;5:270.

99. Singh S, Singh PP, Singh AG, et al. Anti-diabetic medications and the risk of hepatocellular cancer: a systematic review and meta-analysis. Am J Gastroenterol 2013;108:881-91.

100. Ampuero J, Romero-Gomez M. Prevention of hepatocellular carcinoma by correction of metabolic abnormalities: role of statins and metformin. World J Hepatol 2015;7:1105-11.

101. Chen HH, Lin MC, Muo CH, et al. Combination therapy of metformin and statin may decrease hepatocellular carcinoma among diabetic patients in Asia. Medicine (Baltimore) 2015;94:e1013.

102.Chen HP, Shieh JJ, Chang CC, et al. Metformin decreases hepatocellular carcinoma risk in a dosedependent manner: population-based and in vitro studies. Gut 2013;62:606-15.

103.Donadon V, Balbi M, Mas MD, et al. Metformin and reduced risk of hepatocellular carcinoma in diabetic patients with chronic liver disease. Liver Int 2010;30:750-8.

104. Hassan MM, Curley SA, Li D, et al. Association of diabetes duration and diabetes treatment with the risk of hepatocellular carcinoma. Cancer 2010;116:1938-46.

105. White DL, Kanwal F, El-Serag HB. Association between nonalcoholic fatty liver disease and risk for hepatocellular cancer, based on systematic review. Clin Gastroenterol Hepatol 2012;10:1342-1359.e2.

106. Calle EE, Rodriguez C, Walker-Thurmond K, et al. Overweight, obesity, and mortality from cancer in a prospectively studied cohort of US adults. N Engl J Med 2003;348:1625-38.

107.Liu Y, Wu F. Global burden of aflatoxin-induced hepatocellular carcinoma: a risk assessment. Environ Health Perspect 2010;118:818-24.

108. Qian GS, Ross RK, Yu MC, et al. A follow-up study of urinary markers of aflatoxin exposure and liver cancer risk in Shanghai, People's Republic of China. Cancer Epidemiol Biomarkers Prev 1994;3:3-10.

109. Hsu IC, Metcalf RA, Sun T, et al. Mutational hotspot in 
the p53 gene in human hepatocellular carcinomas. Nature 1991;350:427-8.

110. Bressac B, Kew M, Wands J, et al. Selective G to T mutations of $\mathrm{p} 53$ gene in hepatocellular carcinoma from southern Africa. Nature 1991;350:429-31.

111. Ozturk M. p53 mutation in hepatocellular carcinoma after aflatoxin exposure. Lancet 1991;338:1356-9.

112.Elmberg M, Hultcrantz R, Ekbom A, et al. Cancer risk in patients with hereditary hemochromatosis and in their first-degree relatives. Gastroenterology 2003;125:1733-41.

113. Harrison SA, Bacon BR. Relation of hemochromatosis with hepatocellular carcinoma: epidemiology, natural history, pathophysiology, screening, treatment, and prevention. Med Clin North Am 2005;89:391-409.

114. Fairbanks KD, Tavill AS. Liver disease in alpha 1-antitrypsin deficiency: a review. Am J Gastroenterol 2008; 103:2136-41.

115.Linet MS, Gridley G, Nyren O, et al. Primary liver cancer, other malignancies, and mortality risks following porphyria: a cohort study in Denmark and Sweden. Am J Epidemiol 1999;149:1010-5.

116. Tansel A, Katz LH, El-Serag HB, et al. Incidence and determinants of hepatocellular carcinoma in autoimmune hepatitis: a systematic review and meta-analysis. Clin Gastroenterol Hepatol 2017;15:1207-1217.e4.

117. Simon TG, Bonilla H, Yan P, et al. Atorvastatin and fluvastatin are associated with dose-dependent reductions in cirrhosis and hepatocellular carcinoma, among patients with hepatitis $C$ virus: results from ERCHIVES. Hepatology 2016;64:47-57.

118. Nkontchou G, Aout M, Mahmoudi A, et al. Effect of longterm propranolol treatment on hepatocellular carcinoma incidence in patients with $\mathrm{HCV}$-associated cirrhosis. Cancer Prev Res (Phila) 2012;5:1007-14.

119. Cancer Genome Atlas Research Network. Electronic address: wheeler@bcm.edu; Cancer Genome Atlas Research Network. Comprehensive and Integrative Genomic Characterization of Hepatocellular Carcinoma. Cell 2017;169:1327-1341.e23.

120. Llovet JM, Montal R, Sia D, et al. Molecular therapies and precision medicine for hepatocellular carcinoma. Nat Rev Clin Oncol 2018;15:599-616.

121. Nault JC, Mallet M, Pilati C, et al. High frequency of telomerase reverse-transcriptase promoter somatic mutations in hepatocellular carcinoma and preneoplastic lesions. Nat Commun 2013;4:2218.

122.Sung WK, Zheng H, Li S, et al. Genome-wide survey of recurrent $\mathrm{HBV}$ integration in hepatocellular carcinoma. Nat Genet 2012;44:765-9.

123. Totoki Y, Tatsuno K, Covington KR, et al. Transancestry mutational landscape of hepatocellular carcinoma genomes. Nat Genet 2014;46:1267-73.

124. Schulze K, Imbeaud S, Letouze E, et al. Exome sequencing of hepatocellular carcinomas identifies new mutational signatures and potential therapeutic targets. Nat Genet 2015;47:505-11.

125.Ahn SM, Jang SJ, Shim JH, et al. Genomic portrait of resectable hepatocellular carcinomas: implications of RB1 and FGF19 aberrations for patient stratification. Hepatology 2014;60:1972-82.

126. Hoshida Y, Nijman SM, Kobayashi M, et al. Integrative transcriptome analysis reveals common molecular subclasses of human hepatocellular carcinoma. Cancer Res 2009;69:7385-92.

127. Boyault S, Rickman DS, de Reynies A, et al. Transcriptome classification of HCC is related to gene alterations and to new therapeutic targets. Hepatology 2007;45:42-52.

128.Zucman-Rossi J, Villanueva A, Nault JC, et al. Genetic Landscape and Biomarkers of Hepatocellular Carcinoma. Gastroenterology 2015;149:1226-1239.e4.

129. Lachenmayer A, Alsinet C, Savic R, et al. Wnt-pathway activation in two molecular classes of hepatocellular carcinoma and experimental modulation by sorafenib. Clin Cancer Res 2012;18:4997-5007.

130.El-Khoueiry AB, Sangro B, Yau T, et al. Nivolumab in patients with advanced hepatocellular carcinoma (CheckMate 040): an open-label, non-comparative, phase 1/2 dose escalation and expansion trial. Lancet 2017;389:2492-502.

131.Sia D, Jiao Y, Martinez-Quetglas I, et al. Identification of an Immune-specific Class of Hepatocellular Carcinoma, Based on Molecular Features. Gastroenterology 2017;153:812-26.

132.Zhou ZR, Liu M, Lu HR, et al. Validation of different staging systems for hepatocellular carcinoma in a cohort of 249 patients undergoing radiotherapy. Oncotarget 2017;8:46523-31.

Cite this article as: Fenton SE, Burns MC, Kalyan A. Epidemiology, mutational landscape and staging of hepatocellular carcinoma. Chin Clin Oncol 2021;10(1):2. doi: $10.21037 /$ cco-20-162 